\title{
OS CAÇADORES DO COOL
}

\author{
ISLEIDE A. FONTENELLE
}

A comunicação mercadológica vem passando por uma fase de transformação. Conseqüentemente, a mídia, de maneira geral, passa pelo mesmo processo, haja vista que é o mercado publicitário quem assegura grande parte dos recursos disponíveis para uma certa ordenação do espaço midiático. Por transformações nas atuais formas de comunicação mercadológica entende-se a evidente queda nos investimentos em anúncios comerciais - propaganda - o que indica um cenário de mudanças nas agências de propaganda e veículos de mídia, concomitante ao surgimento de uma literatura mercadológica que defende novas modalidades de comunicação dos produtos e marcas.

Nesse contexto, as estratégias de produção e comunicação de mensagens voltadas às práticas de consumo assentam-se no conhecimento prévio e profundo da realidade sociocultural mais ampla, o que provoca uma maior pulverização dos canais de acesso ao consumidor (antes bastante restrito ao anúncio comercial impresso e eletrônico, especialmente no caso das grandes marcas); bem como, a mutações formais dos discursos publicitários que, não visando mais atingir "a massa", passam a fazer uso de diferentes linguagens e canais, a depender do "nicho de consumidores" a se alcançar.

As chamadas "pesquisas de mercado de tendências culturais" cujas origens remontam aos anos 1970, mas que ganharam um novo formato e um novo status a partir dos anos 1990 - se destacam como ferramentas essenciais para essas novas formas de estratégias comunicacionais. Nesse sentido, este trabalho visa entender: o que mudou na "cultura de consumo" para que essas pesquisas tenham se tornado tão importantes para as grandes empresas multinacionais; porque e como elas indicam mudanças na forma de se comunicar um produto; e, mais ainda, que alterações elas 
provocam no espaço comunicacional como um todo. Aqui, toma-se por pressuposto o fato de que as informações captadas por essas pesquisas de tendências têm forte influência no direcionamento e/ou redirecionamento estratégico das formas de comunicação mercadológica, no sentido de que tais pesquisas visam, sobretudo, captar as transformações nas mentalidades, nos estilos de vida, nas formas de manifestação do desejo do consumidor, partindo sempre da idéia do "ato de consumo" como o ato social por excelência da sociedade contemporânea, tomando, portanto, o próprio ato de consumo como uma forma de "comunicar".

$\mathrm{O}$ aspecto que melhor sustenta o pressuposto de que as referidas pesquisas se apresentam como um caminho fértil para a compreensão das transformações na comunicação mercadológica está presente na afirmação do estrategista de marketing Al Ries, que coloca que, na sociedade contemporânea, a eficácia das relações públicas é, comprovadamente, superior à do anúncio comercial - propaganda. Por isso mesmo, diz o autor, as empresas precisam inventar constantemente maneiras de estar na mídia (criando e/ou recriando um produto ou conceito), já que a mídia veicula o novo, o surpreendente, o que é "quente" no momento. Daí porque este trabalho assume que as pesquisas de tendências apresentam-se como um espaço necessário para o processo de antecipação permanente, a fim de que as empresas possam sair na frente no lançamento de novos produtos e serviços e gerar notícias na mídia-realidade.

Tendo isso em vista, privilegiar-se-á, nesta análise, sobretudo a forma inerente às pesquisas de tendências, ou seja, a maneira como elas representam um novo estágio do marketing (produção e comercialização da mercadoria) na sociedade contemporânea, na medida em que tais pesquisas são tomadas como identificadoras daquilo que pode vir a comportar valor na sociedade do consumo. E "valor é informação: assim se poderia resumir a essência da dinâmica capitalista econômica contemporânea".

Mais especificamente, o foco de análise será em um tipo muito específico de pesquisa de tendências: a realizada pelas empresas coolhunt ing, voltada para a captação de tendências de consumo em meio à cultura jovem. Desse modo, este artigo pretende contribuir com o campo da comunicação ao buscar destrinchar o nó que liga as práticas do marketing aos campos cultural e comunicacional mais amplos, para entender o que mudou na sociedade, na tecnologia e nas mentalidades, enfim, na cultura de consumo contemporânea, que levou a essa nova configuração mercadológica e midiática e quais os seus impactos para a comunicação. 


\section{AS PESQUISAS EM MARKETING E A EMPRESA COOLHUNTING}

Um certo enfoque sociológico da publicidade compreende o marketing como um produto direto da propaganda. Segundo Lagneau (1981, p. 18), o marketing - "palavra de origem inglesa que designa a tendência das práticas comerciais a racionalizar-se em função do mercado" - teria se originado da necessidade de se compreender, via pesquisas, que tipo de imagem melhor seduziria o consumidor. Trata-se de uma referência histórica que remonta à década de 1930; portanto, ainda ao período no qual procurava-se atrelar imagens a um produto já fabricado para a venda, e onde o objetivo principal era apresentar o próprio produto. $\mathrm{O}$ produto era, portanto, a fonte mesma da imagem, e os meios de veiculação eram fundamentalmente impressos: jornais e cartazes.

A partir das décadas de 1950/60, começa a se dar um processo de substituição do produto pela imagem na sua comunicação, não apenas porque havia uma necessidade objetiva das empresas se diferenciarem (com a explosão de produtos em massa cada vez mais homogêneos), como também devido ao surgimento da televisão que possibilitava a produção de imagens comerciais antes inimagináveis (um "vendedor eletrônico" na sala de visitas da família).

É nesse mesmo período que surgem as pesquisas de motivação (no sentido estrito de procurar o motivo, a razão profunda, pela qual as pessoas consomem, para além da necessidade do produto) para subsidiar uma estratégia de propaganda destinada a vender "não o bife, mas o chiado; não o sabonete, mas o sonho de beleza; não as latas de sopa, mas a felicidade familiar". Uma estratégia que teria partido de um reconhecimento das empresas de que "o triunfo do mercado de massa se baseava, de algum modo bastante profundo, na satisfação das necessidades tanto espirituais quanto materiais dos consumidores..." Hobsbawm (1995, p. 496).

Tratava-se, enfim, de se produzir imagens que, não necessariamente, tivessem relação com o produto, começando um processo de "descolamento da imagem do produto" que culminou, nos anos 1990, na forma de propaganda nonsense, ou seja, aparentemente (e apenas na aparência) uma propaganda não interessada em falar/apresentar o produto e não querendo mais fazer sentido.

Praticamente, a segunda metade do século XX foi marcada, na comunicação comercial, pelo período áureo das agências de propaganda, responsáveis pela criação de anúncios fundados na idéia de transmitir, mais que o produto, imagens. Mas, a partir da década de 1990, começava uma 
"transformação silenciosa" na comunicação mercadológica que só agora está mais evidente: o impacto das inovações tecnológicas que, de um lado, passou a provocar uma grande dúvida sobre a eficácia da propaganda (não só devido ao surgimento do controle remoto, o que tornava o consumidor/telespectador me-nos vulnerável ao assédio do anúncio, como também por conta do desafio apresentado pela produção de imagens cada vez mais indiferenciadas, como outrora foram os produtos); e, de outro, levou a mudanças no padrão de competitividade (a chamada "aceleração da aceleração capitalista" e a necessidade de uma constante "fuga para a frente" no sentido da busca da inovação) que forçaram as empresas a tentar se antecipar às tendências na busca de alguma vantagem competitiva ao saírem na frente no lançamento de algum produto ou serviço.

Tais mudanças podem ser tomadas como tendo forte influência na maneira como se formataram as pesquisas de mercado de tendências culturais a partir da década de 1990. Na verdade, essa forma de pesquisa "de tendências" surgiu desde os anos 1970 a partir de uma constatação do mercado: "às profundas transformações que passam a ocorrer, a partir do final dos anos 1960, grosso modo, nos países capitalistas avançados... ligase a consciência crescente, no âmbito dos estudos de mercado, da importância das chamadas variáveis sociais e, particularmente, das socioculturais, para a determinação dos estilos de vida e padrões de consumo dos agentes sociais", Goldenstein (1990, p. 3).

Assumindo que essas variáveis socioculturais são capazes de permitir o nascimento de novos mercados ou, pelo contrário, de levar velhos mercados ao colapso, as grandes empresas passaram a privilegiar o uso de estudos de tendências no planejamento estratégico de seus negócios. Mas, enquanto nos anos 1970 ainda se podia pensar em mercados de massa, os anos 1990 se vêem com o desafio da segmentação. Assim é que esse novo desafio provoca o nascimento das "coolhunting", empresas "caçadoras do cool', daquilo que pode ser gerador de tendências de consumo. O que essas empresas buscam é fazer uma mediação ainda mais direta entre uma forma de expressão cultural - especialmente da cultura jovem - e uma prática de consumo. Em outras palavras, transformar cultura em mercadoria.

\section{A COOLHUNTING E AS MUDANÇAS SOCIOCULTURAIS}

a evolução das táticas do capitalismo mundial, personalizadas na coolhunter Cayce Pollard [me fez pensar] que estivesse 
inventando também as técnicas de guerrilha de marketing que cito no livro. Mas, depois que ele ficou pronto, descobri que todas as minhas técnicas 'imaginárias' já vinham sendo testadas.

Seria impossível encontrar palavras melhores para demonstrar o cenário preciso no qual se descortinam as propostas de investigação sociocultural das empresas coolhunting, anunciando algo de novo nas práticas de pesquisa e comunicação em marketing, produto do que seria também uma "nova sociedade". Opondo-se às tradicionais pesquisas de mercado - especialmente as quantitativas - a caçada ao cool, conforme dito pelo jornalista e escritor Malcolm Gladwell, visa descobrir quais, dentre as milhares de coisas que estão acontecendo na cultura jovem, serão mais importantes no sentido de constituírem tendências que possam ser transformadas em consumo. Trata-se, portanto, de uma forma de percepção que consiga captar as mudanças sutis nas configurações socioculturais em curso, em detectar padrões e, especialmente, em transformar isso em algo muito rentável, ao ser vendido para empresas ávidas por informações sobre a quem e como vender os seus produtos e ou serviços.

É assim que funciona o negócio de "caçada ao cool", segundo Grossman (2003): quando as pessoas cool - um grupo conhecido pelos marqueteiros como consumidores alfa - começam a falar, ou comer, ou fazer compras de um certo modo, as pessoas não cool os seguirão. Ou seja: observe o que os consumidores alfas estão fazendo hoje e você poderá prever o que a maioria estará fazendo amanhã. E, em uma época de competição acelerada, com empresas obcecadas por inovações permanentes, informações que garantam um investimento seguro valem muito dinheiro, o que gerou "uma indústria pequena, mas vigorosa, completamente dedicada a colher informações desse tipo: os observadores de tendências, que entendem o que é e o que não é cool".

Portanto, ser um caçador do cool é tentar chegar às tendências na fonte, descobrir de onde elas estão vindo. Sabendo disso, é possível sair na frente e, conforme Gladwell (2001) afirma, isso agora é tudo no mundo dos negócios. Ter uma boa idéia de onde as tendências estão vindo também é a chance de influenciar seus movimentos. E, segundo esse autor, em algum momento do desenvolvimento sociocultural, as tendências passaram a ser ditadas de baixo para cima (ao contrário do que afirmaram autores como Thorstein Veblen e George Simmel, acerca do processo de "cópia" das classes menos favorecidas a partir do que era ditado pelas classes ricas) e elas estão ocorrendo em muitas diferentes áreas ao mesmo tempo (música, 
moda, esportes etc.), o que levou muitas corporações a, no início dos 1980, tornaram-se cientes de que não estavam mais mantendo contato com o consumidor e que era impossível para elas prever o que o mercado queria.

A ênfase na busca do cool indica, também, uma passagem da cultura de massas para o mercado de nichos, gerando uma absoluta diversidade a ser explorada em meio a um público cada vez mais heterogêneo. Assim, houve uma mudança de foco metodológico: de padrões sociológicos centrados em paradigmas descritivos de interações e comportamentos sociais, para abordagens mais antropológicas, centradas na observação cultural.

Assim, quando há uma mudança no status das variáveis demográficas definidas como o principal determinador da influência social, o campo se abre. Segundo Gladwell (2001), dizer que alguém é do sexo masculino, ganha U\$75.000, vive em NY e tem 37 anos não representa mais fatos notáveis acerca dessa pessoa e do seu papel em torno de seus amigos. Com isso, a porta se abre para um número possível de caminhos para entender essa pessoa, e todos esses possíveis caminhos são mais flexíveis do que os duros fatos demográficos. E todos são matéria de interpretação e de análise cultural. Daí porque os pesquisadores coolhunters formam um time menos preciso e objetivo que seus predecessores, com formas de leitura da realidade cultural menos confortáveis que as medidas quantitativas e, portanto, mais subjetivas.

Mas, finalmente, do que se trata o cool? Antes de mais nada, tratase de uma palavra que não permite uma tradução literal para o português. Cool pode ser algo simplesmente "legal" mas, quando se trata de pensar o cool associado à pesquisa de mercado de tendências culturais, ele representa o "novo legal", mas um novo que já foi adotado antes por uma minoria, e que pode vir a ser adotado por uma grande maioria. Segundo Grossman (2003), o cool pode ser considerado o recurso natural mais precioso da América: uma substância invisível, impalpável, que pode fazer uma determinada marca de qualquer mercadoria - um tênis, uma calça jeans, um filme de ação - fantasticamente valioso. Ser cool tem a ver com estabelecer tendências, a partir da influência pessoal dentro de uma rede social específica (nicho).

Gladwell (1997) também explica: o cool está relacionado, historicamente, ao que ele chama de "cultura de rua", que provocou tendências que, devidamente captadas pelos coolhunters, renderam bilhões às empresas que adotaram suas idéias: a compreensão da era de simplicidade e autenticidade que teria levado a Converse a fazer uma volta ao seu tênis One Star, por exemplo, e que catapultou a marca para o clube das marcas cool (não por acaso, o calçado usado por Kurt Cobain, um dos grandes 
baluartes dessa América cool, como revelou a famosa foto do roqueiro morto, estendido no chão). Daí porque coolhunting é, na visão de Gladwell, apenas uma coleção de observações espontâneas e prognósticos que diferem de um momento para o outro e de um coolhunter para outro. Enfim, o cool é alguma coisa que você não pode controlar e precisa de alguém para achá-lo e falar a você o que ele é. Nas palavras de um desses profissionais: "a artimanha do coolhunter não é apenas ser capaz de lhe dizer quem é diferente, mas ser capaz de dizer quando aquilo que é diferente representa alguma coisa verdadeiramente cool".

Observando a rotina de um coolhunter, Gladwell (1997) nos relata como, depois de um dia inteiro em uma rua onde caça as tendências, ele retorna à empresa e se reúne com especialistas em marketing, representantes de vendas e desenhistas e reconecta-os à rua, assegurando-se de que eles levarão o produto certo, no lugar certo e no preço certo. Nesse caso, o trabalho do coolhunter é bem específico. Mas ele pode ter uma ambição maior, como no caso do que é feito pelo "L Report", um tipo de relatório realizado pela empresa coolhunting Lambesis, que visa construir um tipo de grande matriz do cool, buscando compreender não apenas o tipo de tênis, ou de roupa, ou de cosmético que os jovens gostam, mas muitas outras coisas. Para isso, quatro vezes ao ano, representantes da empresa seguem para seis cidades representativas da América - Nova York, Los Angeles, San Francisco, Austin-Dallas, Seatlle e Chicago - e as informações obtidas são analisadas e vendidas às agências de publicidade (e outros tipos de empresas) por vinte mil dólares ao ano.

O concorrente à altura do "L Report" é o relatório "Hot Sheet" criado por Irma Zandl, considerada, do ponto de vista do formato do negócio, a fundadora do negócio coolhunting. Zandl foi a criadora do termo "consumidor alfa" e, desde 1986, se dedica à tarefa de caçar tendências jovens, algo que começou intuitivamente, pois ela afirma que desde o início ela sabia se algo se tornaria $\mathrm{cool}$, mas não sabia como ela sabia disso. Daí porque Zandl montou a sua empresa e passou a buscar informações mais concretas, inventando um modo novo de analisar tendências e criando com isso toda uma indústria. Hoje, ela administra um grupo de 3.000 jovens, entre 8 e 24 anos, etnicamente, geograficamente e com gênero diversificados que, com uma Polaroid na mão, e um questionário na outra, saem em busca do cool.

Mas na era da internet exige-se métodos mais sofisticados de caça ao $\mathrm{cool}$, na medida em que, segundo os próprios coolhunters, a internet torna o tempo do cool cada vez mais rápido e mais descartável. A LookLook, empresa coolhunting de propriedade de Dee Dee Gordon e Sharon 
Lee, foi criada para capitalizar em cima dessa própria tendência: dando-se conta de que lápis e papel já não correspondia mais ao tipo de pesquisa necessária a uma época na qual os jovens usam mensagens instantâneas, a Look-Look foi fundada a partir da implantação de uma metodologia de pesquisa baseada em informações on-line, com uma rede de cerca de 10.000 correspondentes de campo que vasculham a cultura jovem com câmeras digitais e enviam mensagens de festas, concertos e eventos esportivos para os especialistas em informações da cultura jovem da LookLook estudar cuidadosamente.

Segundo Lee, a internet é o grande recurso para ambos - os correspondentes e a Look-Look -, já que a possibilidade de aprender sobre coisas, com a velocidade com a qual a informação viaja, tem acelerado de tal modo que você realmente precisa de fontes em tempo real para dizer: é isso que está acontecendo agora. E "isso" está se movendo cada vez mais rápido. Lee lembra que, se antes as coisas levavam um ano e meio a dois anos para se moverem, agora isso pode levar apenas alguns meses. Daí a necessidade dessa grande rede em tempo real e, por conta dela, segundo as sócias da Look-Look, é possível se testar hipóteses com qualquer tipo e tamanho de amostra e obter respostas imediatas. O que Grossman (2003) reitera, ao assumir que é preciso respeitar a absoluta eficiência na coleta de informações da Look-Look, que extrai o que há de mais cool na cultura jovem com uma velocidade espantosa e em quantidades sem precedentes.

E extraem porque, segundo dados da Look-Look, seus correspondentes vivem na cultura jovem, não fora dela. Eles têm autonomia para encontrar e informar sobre as coisas interessantes que estão acontecendo, dando insigths sobre o que poderá ser ou não embalado para consumo, baseados no que eles estão vivenciando, vendo acontecer, contra o que se poderia pensar que está acontecendo. Daí porque, quando realiza suas pesquisas, a Look-Look não busca apenas entender o que os jovens acham de roupas e cosméticos, mas de questões mais profundas, tais como suas esperanças, sonhos, o que eles pensam sobre o futuro, seus familiares.

$\mathrm{O}$ foco da Look-Look sobre a cultura jovem é defendido a partir de uma visão profundamente otimista da juventude que, segundo suas sócias, é uma cultura vibrante, excitante, em busca de sua própria identidade e de seus próprios pensamentos e questões. E por que os jovens se tornaram tão importantes? Antes de mais nada, por um motivo claro: a explosão demográfica. Atualmente, só nos EUA, eles são 33 milhões e consomem U\$ 100 bilhões diretamente e U\$ 50 bilhões através da maneira como influenciam seus pais a gastarem. 
Mas Lee aponta outro fator: uma mudança tecnológica, com o boom da internet, que "deu a esses jovens um poder no interior da família, de tornarem-se os chefes tecnológicos de suas casas, está havendo um reforço no conceito de individualidade no interior desta cultura: são jovens que são pensadores originais, mas que não tiveram essa parte de suas personalidades aceitas pelo mundo em geral" (embora, contraditoriamente, um conceito genérico de juventude seja o paradigma por excelência para todo um mercado de consumo baseado no conceito de ser jovem). Segundo Lee, os jovens contemporâneos são otimistas, contrários ao pensamento adulto de que são angustiados, que odeiam coisas e que são obcecados com coisas como o que ocorreu em Columbine. E elas também os acham muito educados, usando a internet para se educarem desde questões políticas até como cozinhar. Por isso, Gordon e Lee consideram que há grande esperança e criatividade. E elas dizem que começaram a perceber isso acontecendo já há alguns anos, quando todos achavam que os jovens só assistiam a MTV e elas perceberam que eles estavam interessados em educar-se, acessando canais mais educativos como o Discovery, em busca do que estava acontecendo de novo. E, ainda segundo elas, isso não significa que eles também não busquem entretenimento, eles apenas provam que nós não podemos separar as coisas e unidimensionar as pessoas jovens.

Em uma perspectiva mais ampla e crítica do ponto de vista da inserção da cultura jovem na cultura de mercado, o texto de Marisa (2002) nos ajuda a entender o que seria essa cultura jovem, já que esse conceito representa diferentes coisas em diferentes tempos e lugares. Na presente cultura dominante ocidental, a juventude pode ser tomada como um conceito, mais do que como uma idade grupal. Nesse caso, ela é a promessa de possibilidade, a liberdade de agir por impulso, rebelião. Se pensarmos a juventude como uma idade específica, ela torna-se um tempo para estabilizar identidade e desejo, logo, torna-se um tempo para situar firmemente as regras e expectativas do nosso mundo social. Juventude é um estágio quando essas poderosas regras e expectativas são fortemente ditadas pela cultura de consumo e seus disseminadores tais como propaganda, música, filmes, televisão, revistas.

De um modo geral, portanto, é na cultura jovem, tomada como subcultura, que se encontrará o que é cool. Mas é preciso fazer uma distinção entre a subcultura jovem marginal - criadora docool - e a subcultura jovem de massa, que consome o cool. Referindo-se ao livro de Dick Hebdige Subculture: the meaning of style - que discute a origem e a função da subcultura como reação à cultura dominante com uma contínua e forte posição 
de oposição, Marisa (2002) conclui que as corporações estão consistentemente atentas para construir uma ponte entre esse marginal - que resiste à cultura como status quo, que a questiona e que se torna, portanto, estabelecedor de tendências -, e o mainstream, consumidor das tendências. Daí a necessidade da criação de um sistema eficiente de observação, apropriação, estandardização e comercialização da cultura jovem e, conseqüentemente, a existência do coolhunter, operador de um sistema altamente complexo de pesquisa exploratória e mercado de nichos, a partir do qual as corporações buscam captar as mudanças e capitalizar em torno delas. A procura é por subculturas que possam produzir coisas que venham a ser "mercadológicas". Trata-se de um sistema de "venda de cultura" e ele é significativo em termos do poder e do potencial que dá à mídia, conglomerados e corporações para explorar, cooptar e apropriar a experiência e a expectativa do que significa ser uma pessoa jovem em nosso mundo social contemporâneo.

Logo, o que o coolhunter faz é oferecer não um modo de imitar a cultura jovem, mas as regras para atuar em seu interior. Daí porque o tipo de direcionamento que essas pesquisas do cool dão às empresas é o de oferecer uma maneira de se criar alguma coisa que irá apelar para o interior dessa cultura jovem, em um nível mais amplo. E as informações culturais obtidas são transmitidas aos clientes corporativos que, por sua vez, usam essas informações para transformar a "tendência" não apenas em um produto mas, especialmente, em uma forma de comercialização que incorpore símbolos, imagens e temas em sua comunicação mercadológica, "para mostrar ao público-alvo que a empresa fala a linguagem deles".

Explica-se: há corporações que estão interessados em pegar um produto que já existe e encontrar uma maneira de apelar à cultura jovem. E elas usam as informações obtidas pela empresa coolhunting para verificar se o produto irá mesmo interessar aos jovens ou se há uma maneira de torná-lo mais interessante. O mesmo ocorre com uma propaganda: as empresas querem testar se um anúncio irá ou não ser relevante para o público-alvo. Ou pode-se querer criar um novo produto ou uma nova marca visando um nicho específico. E usa-se as informações da coolhunting para inspirar os desenhistas do projeto, a ajudálos a direcionar o novo produto no mercado e até mesmo em nomeá-lo e, então, eventualmente, testá-lo.

Portanto, mais do que uma forma de pesquisa sobre que produtos e serviços a lançar, a caçada ao cool é uma maneira de compreender o que e como comunicar. Não por acaso, há uma relação profunda entre a 
idéia de $c o o l$ e de marca publicitária, tendo em vista a força que a marca tem em comunicar um produto e o quanto o melhor dos produtos pode ser descartado em função de uma marca ser considerada "não cool". Como exemplo, Gladwell (1997) narra um episódio relacionado à marca de tênis Reebook, que passou a ser preterida pelos jovens do mundo inteiro em função da ascensão da Nike. Ele nos conta que um dos jovens entrevistados sobre um novo tênis Reebook teria dito que o tênis era realmente cool e que gostaria de usá-lo, se ele não tivesse a marca da Reebook.

A transformação da Apple em uma das marcas mais cool da América torna ainda mais claro esse vínculo entre produto $\mathrm{cool}$ e marca cool: ao lançar o iPod ("player" de música digital) e o serviço de música on-line iTunes Music Store, além do PowerMac G5, a Apple teria se tornado, segundo os coolhunters, uma das empresas consideradas "mais quentes" na cultura jovem, seguida das marcas Coca-Cola, Levi's e Nike. A marca Apple tornouse cool porque, segundo a coolhunter Claire Brooks (da empresa de pesquisa Lambesis), a empresa é uma grande criadora de tendências, de estilo de vida". Dá-se, portanto, uma volta no círculo: depois de pesquisadas as tendências mais cool na formatação dos produtos e serviços, é preciso que isso seja assimilado pelos chamados "inovadores", aqueles primeiros na cadeia dos que adotam o cool e espalham a tendência. E, segundo afirmam alguns coolhunters, eles precisam ser, realmente, convencidos de que algo é realmente $\mathrm{cool}$, já que são os mais difíceis de serem convencidos por uma campanha de marketing. Mas, uma empresa também pode intervir no ciclo do cool, fazendo uma celebridade considerada cool adotar os seus produtos. A Apple tornou-se uma marca cool entre os jovens também devido "ao fato de que as celebridades, que eles consideram cool - como músicos, cineastas e designers -, usam os produtos da empresa".

Durante muito tempo, o espaço por excelência para a disseminação das tendências em meio à cultura jovem de massa foi - e ainda continua sendo em grande medida a mídia. E, segundo uma vertente de leitura desse fato, isso teria resultado em uma relação simbiótica entre a mídia e a juventude, com uma olhando para a outra para constituir sua própria identidade, ao ponto de se afirmar que a cultura jovem e a cultura da mídia são agora uma só coisa. Por outro lado, observa-se uma outra leitura que aponta uma relação problemática entre os jovens e a mídia: uma relação de desconfiança e de desprezo por parte dos primeiros com relação ao que a mídia lhes oferece.

Segundo a leitura de Gordon; Lee (2001), "não é que esses jovens odeiem todo o mercado, todo o marketing e toda a mídia. É que eles sabem o que está sendo vendido, eles sabem tudo sobre marketing. Eles 
foram crescendo com a desconstrução da propaganda. E o que precisa ser feito é se criar algum tipo de conexão emocional com eles, onde eles possam estar interessados e eles respeitem você e sejam respeitados. E o desrespeito que geralmente ocorre é fruto de um entendimento muito superficial dessa cultura - de tomá-los como consumidores estúpidos. Mas a verdade é que eles querem honestidade, autenticidade da companhia. Não se trata apenas de vender o produto, mas estabelecer com eles um diálogo de longo tempo".

Daí a necessidade de se entender realmente a cultura jovem, segundo Gordon; Lee (2001), que acreditam que as pessoas espertas do mercado estão se perguntando como criar uma relação face a face, de diálogo com essa cultura. Como exemplo, elas falam da relação com o "marketing da raiva", produto do que seria uma maneira de ser dessa juventude. Há aqueles no mercado que partem das sutilezas, se perguntando: se nada mais choca os jovens (porque eles estão expostos a tudo), como eu tomo tudo isso e crio uma outra forma de relação com eles? Como falar com eles de um modo real e não artificial? E, enquanto isso, os retardatários estão dizendo: bem, nós devemos apenas ser mais violentos ou mais extremos. Daí porque, segundo as sócias da Look-Look, pode-se dizer que $20 \%$ das companhias e agências de propaganda estão vivendo nas sutilezas. Os outros $80 \%$ são os retardatários que irão segui-los: assim como os jovens, há também os clientes inovadores e aqueles que o seguem.

E o que esse retrato nuançado da cultura jovem aponta, juntamente com as novas formas de comunicação mercadológica adotadas pelos chamados clientes inovadores, é que a mídia está na berlinda, do ponto de vista de um espaço privilegiado da comunicação mercadológica. Não por acaso, os investimentos em propaganda estão caindo. Talvez, nesse caso, a referência a uma das mais recentes campanhas publicitárias da Coca-Cola - que mostra a atriz Penelope Cruz arrotando - seja exemplar. Muito se discutiu a "criatividade" da campanha em busca de impacto junto ao telespectador. Mas, especialmente, o quanto essa busca tem, hoje, um limite concreto: a dispersão da audiência com centenas de canais a cabo, videogames, internet, iPods e telefones celulares. Portanto, não basta apenas uma boa criatividade se, por trás, há a questão central: alguém irá ver? Quem irá ver? Como atingir o público? Ciente disso, um dos mais altos executivos da Coca-Cola admite a necessidade urgente de se repensar a abordagem da propaganda de marca, apostando nas parcerias entre a CocaCola e as empresas provedoras de entretenimento. Como consequiência dessa aposta, foram inaugurados "espaços experimentais" em shopping cen ters nas cidades de Chicago e Los Angeles, lugares onde os adolescentes podem sentar, ver vídeos, ouvir músicas e, obviamente, beber Coca-Cola. 
$\mathrm{Na}$ busca por espaços alternativos para comunicar suas marcas - via produtos e serviços -, os marqueteiros apelam aos dados apontados pelos coolhunters: de que o produto será grandemente abraçado se ele apelar para o tipo de jovem que irá apontar as tendências junto a seus pares - o disseminador da tendência - e, com isso, começar um processo de "propaganda boca a boca". Daí porque entender o cool é tão valioso para o marketing também do ponto de vista da comunicação do produto. É um atalho, especialmente no interior do negócio de moda e cinema, por exemplo, que são negócios que, segundo os analistas de mercado, têm uma forte dimensão de contágio social.

E a busca por esses espaços alternativos está chegando a tal ponto que as fronteiras entre o coolhunter e o publicitário estão se diluindo absurdamente. Não por acaso, os coolhunters já estariam selecionando jovens representativos de seu nicho, que são pagos para convencer, através da propaganda boca a boca, um outro número significativo de jovens pessoas a comprar certos produtos. Essa prática estaria sendo utilizada baseada na crença de que as pessoas jovens acreditarão em outras pessoas jovens, mais do que na mídia (Marisa, 2002).

Tal fato guarda uma relação muito próxima com o que tem sido praticado como "marketing oculto", uma nova técnica de comunicação de um produto que parte do princípio de que está cada vez mais difícil alcançar a atenção do consumidor através do anúncio tradicional. Devido a isso, as agências de publicidade da Madison Avenue têm desenvolvido uma forma de apresentação do produto de maneira que não provoque resistência no possível consumidor, simplesmente porque ele não sabe que se trata de uma abordagem do mercado.

Algumas técnicas desse "marketing oculto" foram apresentados em um programa do 60 minutes de forma detalhada, a partir de três quadros específicos: uma nova luva para jogadores de videogames; um telefone celular que tira fotos; o lançamento de um novo filme. No primeiro caso, dois "agentes ocultos" foram a uma cafeteria Starbucks e começaram a brincar com a luva, de modo a chamar a atenção dos presentes para aquele gadget - o que, de fato, aconteceu. No segundo caso, em uma campanha chamada "turistas falsos", um casal de "agentes ocultos" aborda algumas pessoas na rua pedindo a elas que tirem fotos com seu novo celular, a fim de fazer com que essas pessoas conheçam o produto. No terceiro e último caso, um adolescente, de 13 anos, entra em uma sala de bate-papo e começa a falar de um filme, visando que o assunto venha à tona e o filme seja discutido e, obviamente, gere interesse de ser visto. 
Não por acaso, o professor de comunicação de uma universidade em Vancouver, Gary McCarron, adverte que o público está, mesmo, imune à propaganda tradicional e que as novas pesquisas indicam que a propaganda que não parece propaganda é o novo modo de captar mentes "esgotadas" pelo excesso de anúncios comerciais (Ritter, 2003). Portanto, esse é um assunto que já está fazendo parte da pauta do novo marketing, embora as problemáticas questões éticas estejam apenas começando.

A principal delas é que a comunicação mercadológica rompeu as fronteiras da mídia e embrenha-se, cada vez mais, na comunicação de uma forma mais ampla e torna-se cada vez mais comercial. Já sabemos o quanto a relação entre mídia e mercado tem sido profundamente debatida, questionada, problematizada. Mas, se a comunicação mercadológica está invadindo outros campos da sociabilidade humana, para além do espaço midiático, isso mostra transformações não apenas nos meios midiáticos, mas na própria comunicação social, indicando novas configurações socioculturais e, especialmente, novas relações de poder em curso que precisam investigadas.

ISLEIDE FONTENELLE é doutora em Sociologia pela USP, com pós-doutorado em Psicologia Social pela PUC-SP/Fapesp.

\section{REFERÊNCIAS BIBLIOGRÁFICAS}

BLECHER, Nelson. A reinvenção da propaganda. In: Revista Exame, nº. 24, 26/11/03.

DELEUZE, Gilles. O ato de criação. Folha de São Paulo. São Paulo, 27 jun. 1999. Mais!, p. 4. EISENBERGER, Daniel. It's an ad, ad, ad, world. Time. 02 set. 2002.

EWEN, Stuart. Leo Burnett: Sultan of Sell. Revista Time, v. 152, nº. 23, p. 92-95, 07/12/98 (Special Issue: Builders and Titans of the 20th. Century; Latin American Edition. p. 94).

FINANCIAL TIMES. Vender a imagem da Coca-Cola é uma tarefa difícil. Trad. Danilo Fonseca. 10 mar. 2004. Disponível em: <http://noticias.uol.com.br/midiaglobal/fintimes/ult579u1021.jhtm>. Acesso em: 11 mar 2004.

FONTENELLE, Isleide. O nome da marca: Mcdonald's, fetichismo e cultura descartável. São Paulo: Boitempo Editorial/Fapesp, 2002.

GIBSON, William. "Pattern Recognition". Entrevista concedida a Folha de S.Paulo/Ilustrada, 03 jun. 2003.

GLADWELL, Malcolm. The merchants of cool: interviews. Frontline. PBS. WGBH, Boston, MA. 27 Fev. 2001. Disponível em: <http://www.pbs.org/wgbh/pages/frontline/shows/ cool/interviews/gladwell.html>. Acesso em: 22 jul 2004.

GLADWELL, Malcolm. The coolhunt. The New Yorker. 17 mar. 1997. Disponível em: <http://www.gladwell.com/1997/1997 0317 a cool.htm>. Acesso em: 22 jul 2004.

GOLDENSTEIN, T. Gisela. Comportamento do consumidor e estudos de tendências. São Paulo: Fundação Getúlio Vargas: Núcleo de Pesquisas e Publicações. Série Textos Didáticos II, 1990. 
GORDON, D.; LEE, S. The merchants of cool: interviews. Frontline. PBS. WGBH, Boston, MA. 27 Fev. 2001. Disponível em: <http://www.pbs.org/wgbh/pages/frontline/shows/ cool/interviews/gordonandlee.html>. Acesso em: 22 jul 2004.

GROSSMAN, Lev. The quest for cool. Time. 08 set. 2003. (Special Report: What's Next)

HOBSBAWM, Eric. Era dos extremos: o breve século XX, 1914-1991. São Paulo. Companhia das Letras, 1995.

JAMESON, Fredric. Fear and loathing in globalization. New Left Review. nº. 23, Septemberoctober, 2003.

KAHNEY, Leander. Apple vira preferência entre jovens. Wired News, 04/09/2003. Disponivel em: <http://br.wired.com/wired/cultura/0\%2C1153\%2C14156\%2C00 .html>. Acesso em: 22 abr. 2004.

LAGNEAU, Gérard. A sociologia da publicidade. São Paulo: Cultrix e Edusp, 1981.

MARISA, Princess. Style Biters: the commodification and commercialization of youth culture. Individualized Studies Thesis. Course Director John McCullough. 11/Jun/2002. Disponível em: <www.princessmarisa.com/media/stylebiters.doc>. Acesso em: 22 jul 2004.

MARSHALL, Leandro. O jornalismo na era da publicidade. São Paulo: Summus Editorial, 2003.

RIES, Al \& Ries, Laura. As 22 consagradas leis de marcas: como transformar seu produto ou serviço em uma marca mundial. São Paulo, Makron Books, 2000.

RIES, Al.; Ries, Laura. A queda da propaganda: Da Mídia Paga à Mídia Espontânea. Rio de Janeiro: Campus. 2002.

RIFKIN, Jeremy. A era do acesso: a transição de mercados convencionais para networks e o nascimento de uma nova economia. São Paulo: Makron Books, 2001.

RITTER, Jana. Buyer Beware: uncovering undercover advertising. The Galt Global Review. 18 mar. 2003. Disponível em: <http://www.galtglobalreview.com/business/ buyer_beware.html >. Acesso em 22/07/2004

SAFER, Morley. Undercover Marketing Uncovered. 60 minutes. CBSNews. 23 out. 2003. Disponível em: <http://www.cbsnews.com/stories/2003/10/23/60minutes/printable 579657.shtml>. Acesso em 12/03/2004.

SCHWARTZ, Gilson. Prefácio in: Martins, J. R. \& Blecher, Nelson. O império das marcas. São Paulo: Negócio Editora, 1997.

SENNETT, Richard. O declínio do homem público: as tiranias da intimidade. São Paulo: Companhia das Letras, 1988.

THE MERCHANTS OF COOL: A report on the creators and marketers of popular culture for teenagers. Frontline. Narr. Douglas Rushkoff. Writ. Rachel Dretzin. Dir. Barak Goodman. Prod. Barak Goodman and Rachel Dretzin. PBS. WGBH, Boston, MA. 27 Feb. 2001. Disponível em: <http://www.pbs.org/wgbh/pages/frontline/shows/cool/>. Acesso em: 22 jul 2004

ZYMAN, Sergio. O fim do marketing como nós conhecemos. Rio de Janeiro: Editora Campus, 1999. 